\title{
Crisis de llanto, irritabilidad y masa en el hemiabdomen derecho no siempre son sinónimos de invaginación intestinal
}

\author{
I. Carabaño Aguadoa , E. La Orden Izquierdo ${ }^{a}$, FJ. Pelayo Baezaa , G. Gallardo Madueño \\ aServicio de Pediatría. Hospital Infanta Elena.Valdemoro, Madrid. España.

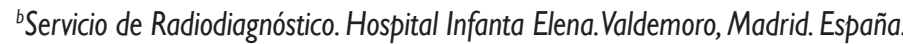

\begin{abstract}
Resumen
La retención urinaria aguda en niños está poco descrita en la bibliografía médica. No hay un claro predominio de afectación por sexo, y su mediana de edad es cuatro años. Puede ser primaria (si aparece en relación con problema nefrourológicos) o secundaria a diversos procesos (cirugía, inmovilidad, trastornos neurológicos crónicos, retraso mental, consumo de drogas, anticolinérgicos, estreñimiento). Clínicamente, puede recordar a una invaginación intestinal, y cursar con dolor abdominal intenso e irritabilidad. Su tratamiento consiste en la evacuación de la orina mediante sondaje. Conviene hacer esta por etapas, si el volumen de la vejiga es muy alto, para evitar la hematuria ex vacuo.
\end{abstract}

Palabras clave: Retención urinaria. Invaginación intestinal. Diagnóstico. Niños.

Crying, irritability and right abdominal mass are not always synonyms of intussusception

Abstract

Acute urinary retention in children is seldom described in medical literature. There is no predominance of sex, and their median age is four years. It can be primary (nephrourological diseases) or secondary to different conditions (surgery, immobility, chronic neurological disorders, mental retardation, drugs abuse, anticholinergics, constipation). It can simulate an intussusception, with severe abdominal pain and irritability. The treatment is the evacuation of urine by catheterization. It should be done in stages if the bladder volume is very high, to avoid ex-vacuo hematuria.

Key words: Urinary retention. Intussusception. Diagnosis. Children.

\section{Introducción}

Muchas veces en Medicina nos enfrentamos a cosas que no son lo que parecen, si bien lo más frecuente es lo más frecuente. De este modo, la mezcla de crisis de llanto paroxístico e irritabilidad por dolor abdominal entre los tres meses y los seis años de edad suele esconder una invaginación intestinal, aunque no siempre sea así. En el caso clínico que a

Iván Carabaño Aguado, carabano1975@hotmail.com

Los autores declaran no presentar conflictos de intereses en relación con la preparación y publicación de este artículo. 
continuación se expone, presentamos a una niña de dos años de edad, sin antecedentes de interés, y que padecía una sobredistensión vesical, hecho que motivó un mimetismo clínico con una invaginación intestinal.

\section{Caso clínico}

\section{Anamnesis}

Niña de dos años y siete meses de edad que acude al Servicio de Urgencias de nuestro hospital por presentar una historia de tres horas de evolución, consistente en llanto, irritabilidad y una doble secuencia de encogimiento-estiramiento de los miembros inferiores. Un vómito aislado. Afebril. A pesar de tener un hábito intestinal regular (tres deposiciones diarias), en las últimas 12 horas no había emitido heces. Los padres no refieren ingesta de fármacos ni relación de la sintomatología con la micción.

\section{Antecedentes personales}

Embarazo controlado sin incidencias. Parto eutócico a las 39 semanas y 3 días. No precisó reanimación neonatal. Peso al nacer: $3170 \mathrm{~g}$. Longitud al nacer: $49 \mathrm{~cm}$. Pruebas endocrinometabólicas normales. Periodo neonatal sin incidencias. Recibió leche materna durante cuatro meses. Leche infantil desde entonces. Diversifica- ción alimentaria según las pautas dictadas por su pediatra de zona, sin incidencias. Sin ingresos ni cirugía previos. Vacunada según el calendario vigente en la Comunidad de Madrid. No constan reacciones adversas a medicamentos ni a alimentos.

\section{Antecedentes familiares}

Madre de 32 años, sana. Dos gestaciones, ningún aborto. Los dos hijos vivos. Padre con rinoconjuntivitis estacional por sensibilización a polen de gramíneas. No consanguíneos. El otro hijo, de cinco años, está sano.

\section{Exploración física}

Peso: 14,300 kg (percentil $\left.70\left[P_{70}\right]\right)$, longitud: $92 \mathrm{~cm}\left(\mathrm{P}_{70}\right)$. Temperatura: $36,8^{\circ} \mathrm{C}$. Frecuencia cardiaca: 110 latidos por minuto, frecuencia respiratoria: 26 respiraciones por minuto. Tensión arterial: 98-56 mm Hg. Saturación de $\mathrm{O}_{2}: 99 \%$.

Irritable, con buen color de piel y mucosas. Sin exantema ni petequias. Buen estado de hidratación y perfusión periférica. No signos de dificultad respiratoria. Auscultación pulmonar: buena ventilación bilateral, sin ruidos sobreañadidos. Auscultación cardiaca: tonos rítmicos, sin soplos. Abdomen: doloroso en el hemiabdomen derecho, con empastamiento y sensación de masa a di- 
cho nivel y en la región periumbilical. Signos meníngeos negativos. Sin focalidad neurológica.

\section{Pruebas complementarias}

- Ecografía abdominal 1 (figura 1): hígado de tamaño normal, borde liso y ecogenicidad homogénea, sin lesiones focales. No dilatación de la vía biliar. Vesícula biliar de tamaño normal, con pared fina, sin imágenes litiásicas en su interior. Área pancreática visualizada y bazo sin alteraciones ecográficas significativas. Riñones de tamaño y forma normales. Vejiga marcadamente distendida, que alcanza un volumen de $458 \mathrm{ml}^{3}$. Sin líquido libre intraabdominal. No hay claras imágenes de invaginación intestinal, aunque la valoración se encuentra dificultada por la distensión vesical. Conclusión: hiperdistensión vesical.

- Ecografía abdominal 2 (figura 2): dentro de los márgenes de la normalidad.

- Sistemático de orina: sin alteraciones. Urocultivo: estéril.

Figura 1. Imagen ecográfica en la que se objetiva una distensión vesical significativa, correspondiente a un volumen vesical casi cuatro veces superior al normal para edad.

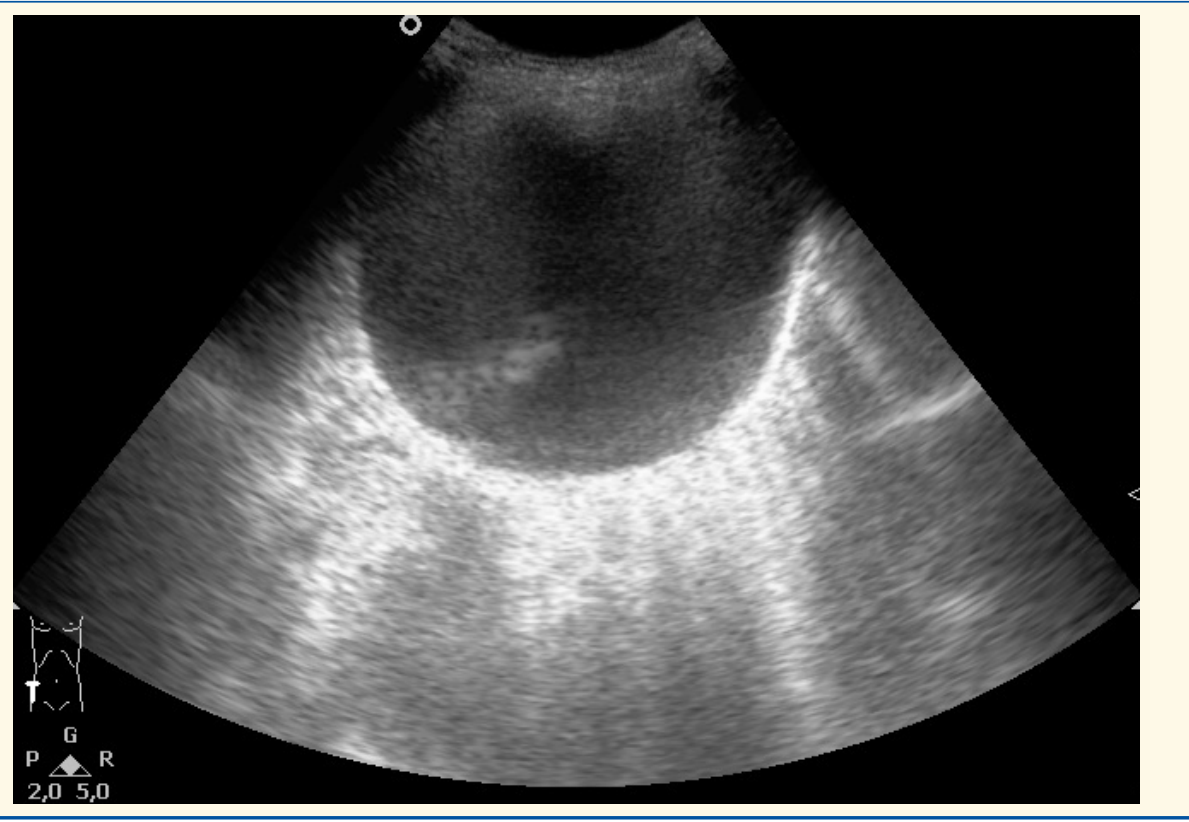


Figura 2. Imagen ecográfica de la vejiga urinaria prácticamente vacía, tras su descompresión por el sondaje.

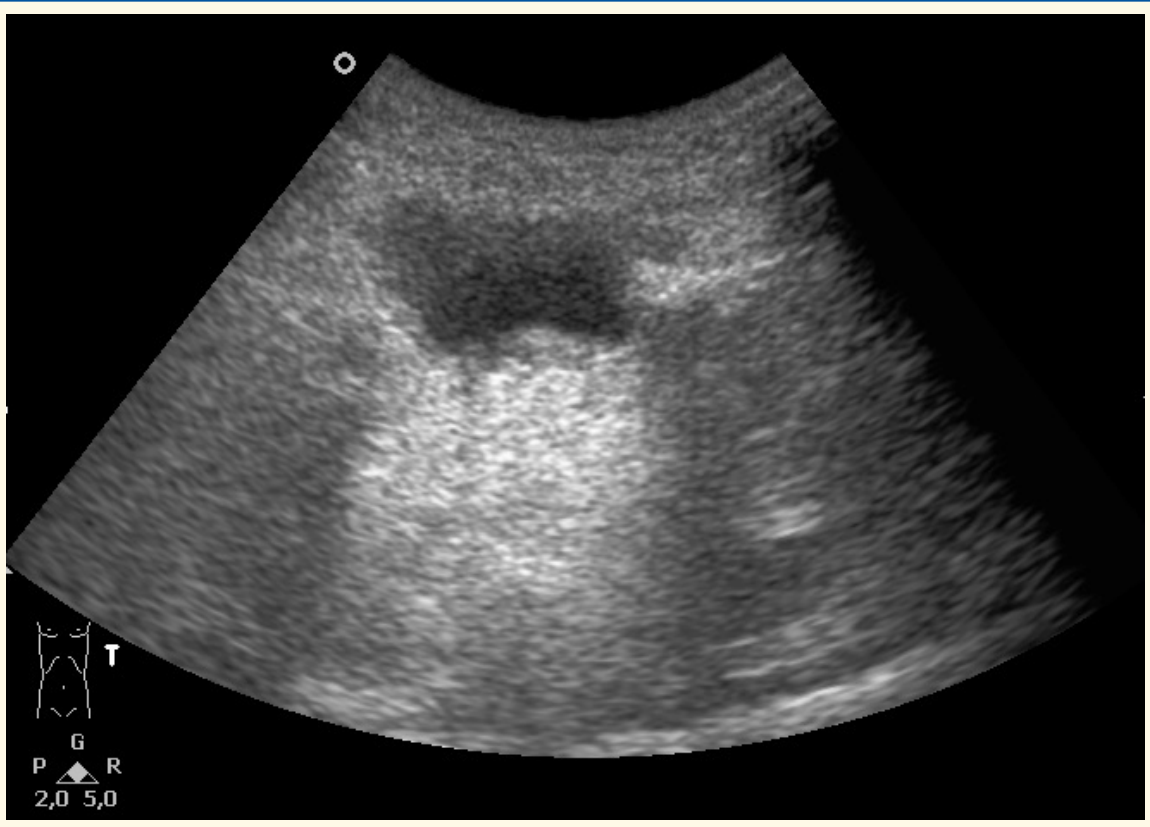

\section{Discusión}

La invaginación intestinal es la causa más frecuente de obstrucción intestinal entre los tres meses y los seis años de vida. Su curso clínico habitual consiste en la presencia de crisis de irritabilidad, dolor abdominal importante y encogimiento o estiramiento de piernas. Suele estar precedida por vómitos, y continuarse con una secuencia de decaimiento, palidez, letargia y exteriorización de heces hemorrágicas "en jalea de grosella". Inicialmente, la situación de nuestra paciente fue enfocada como una invaginación intestinal, máxime teniendo en cuenta que en la palpación del abdomen se percibía una masa en el hemiabdomen derecho, hecho que se objetiva habitualmente en las invaginaciones ileocólicas, que constituyen la localización más frecuente de las invaginaciones".

No obstante, al realizar la ecografía abdominal se constató que no había, en apariencia, imágenes de invaginación intestinal. Destacaba, por el contrario, una marcada distensión vesical (hecho que podía interferir con la correcta visualización de las asas). Para una niña de dos años de edad, el volumen medio de la vejiga urinaria es de aproximadamente 
$120 \mathrm{ml}^{3}$; esto es, 3,75 veces menos del volumen encontrado ${ }^{2}$.

A continuación, se procedió a resolver la sobredistensión vesical mediante sondaje urinario con pinzado periódico, que permitió la evacuación de $450 \mathrm{ml}$ de orina. El dolor de la niña se fue resolviendo de forma progresiva. En la ecografía de control se constató la desaparición del globo, así como la ausencia de imágenes de invaginación intestinal.

Encontramos que el interés divulgativo de este caso descansa en los siguientes puntos: en primer lugar, si los padres no lo refieren, rara vez el pediatra sospechará una retención urinaria aguda; en segundo lugar, el abordaje diagnóstico del llanto de origen abdominal en los niños pequeños suele estar artefactado por una exploración física dificultosa, dada la poca/nula colaboración; en tercera instancia, el diagnóstico diferencial de una invaginación intestinal se ha de plantear,
Tabla 1. Diagnóstico diferencial de la invaginación intestinal

- Gastroenteritis aguda

- Colelitiasis sintomática

- Enterocolitis

- Divertículo de Meckel

- Púrpura de Schönlein-Henoch

principalmente, con entidades que afectan propiamente al tubo digestivo (tabla 1) ${ }^{3}, y$-en consecuencia- se nos pueden escapar las causas extradigestivas; cuarto, la disponibilidad de un ecografista con experiencia en pacientes pediátricos es clave a la hora de enfocar el diagnóstico diferencial; quinto, para los gastroenterólogos infantiles resulta de utilidad saber que la retención urinaria aguda puede mimetizar clínicamente una invaginación intestinal.

Con respecto a la retención urinaria aguda en niños, cabe destacar que ape-

Tabla 2. Etiología de la retención urinaria aguda

\begin{tabular}{ll}
\hline Primaria & Secundaria \\
\hline - Litiasis renal & - Poscirugía \\
- Disfunción vesical neurogénica & - Inmovilidad \\
- Traumatismo vesical & - Trastornos neurológicos crónicos \\
- Síndrome megauréter-megavejiga & - Retraso mental \\
- Cistitis & - Consumo de drogas \\
- Ureterocele & - Anticolinérgicos \\
- Himen imperforado & - Estreñimiento \\
- Tumores & \\
- Megautrículo prostático & \\
\hline
\end{tabular}


nas está descrita en la literatura médica. consiste en la evacuación de la orina meParece que no hay un claro predominio diante sondaje. Si el volumen de la vejiga de afectación por sexo, y su mediana de es muy alto, conviene hacer esta por etaedad es cuatro años. En la tabla 2 se ex- pas, para evitar la hematuria ex vacuo $0^{7-8}$. ponen sus causas principales ${ }^{4-6}$.

El tratamiento de la retención urinaria aguda por distensión vesical primaria

\section{Bibliografía}

1. Carabaño Aguado I, Díez R, Gómez Patiño J. Invaginación intestinal crónica. An Pediatr (Barc). 2010;72:371-2.

2. Feier D, Fufezan O, Tătar S, Cobzac G, Popa RT. Ultrasonography contribution in reno-urinary anmalies: a cohort study. Med Ultrason. 2010;12: 205-21.

3. Niramis $R$, Watanatittan $S$, Kruatrachue A, Anuntkosol M, Buranakitjaroen V, Rattanasuwan T et al. Management of recurrent intussusception: nonoperative or operative reduction. J Pediatr Surg. 2010;45:2175-80.

4. Vaddi SP, Devraj R, Reddy V, Vikram A, Dayapule $S$, Munisami R. Urethral steinstrasse cau- sing acute urinary retention. Urology. 2011;77: 594-5.

5. Asgari SA, Mansour Ghanaie M, Simforoosh $\mathrm{N}$, Kajbafzadeh A, Zare A. Acute urinary retention in children. Urol J. 2005;2(1):23-7.

6. Stankovic C, Mahajan PV. A 16-year-old boy with acute urinary retention. Pediatr Emerg Care. 2007;23(8):573-5.

7. Gatti JM, Pérez-Brayfield $M$, Kirsch AJ, Smith EA, Massad HC, Broecker BH. Acute urinary retention in children. J Urol. 2001;165:918-21.

8. Peter JR, Steinhardt GF. Acute urinary retention in children. Pediatr Emerg Care. 1993;9(4): 205-7. 